\title{
Mindfulness-Based Cognitive Therapy: A Case Study on Experiences of Healthy Behaviors by Clients in Psychiatric Care
}

\author{
Therése Ingvarsson"1, Tommy Nordén ${ }^{1}$, Torsten Norlander ${ }^{1,2 *}$ \\ ${ }^{1}$ Center for Research and Development, Evidens University College, Göteborg, Sweden \\ ${ }^{2}$ Department of Clinical Neuroscience, Karolinska Institutet, Solna, Sweden \\ Email: teaingvarsson@hotmail.com, tommy.norden@evidens4u.se, ${ }^{*}$ at.norlander@mailbox.swipnet.se, \\ torsten.norlander@ki.se
}

Received 19 August 2014; revised 19 September 2014; accepted 19 October 2014

Copyright (C) 2014 by authors and Scientific Research Publishing Inc.

This work is licensed under the Creative Commons Attribution International License (CC BY).

http://creativecommons.org/licenses/by/4.0/

(c) () Op Open Access

\section{Abstract}

The aim of the study was for the first time to investigate patients' own experiences of developing healthy behavior in connection with their participation in Mindfulness-Based Cognitive Therapy (MBCT). Healthy behaviors were defined as those which aimed to improve the individual's wellbeing and physical function. Two women, diagnosed with bipolar illness or depressive episodes, were recruited from a group of clients in psychiatric care who both had been treated according to MBCT. The two clients shared their views of what changes they experienced during the treatment in semi structured interviews. Data analysis was performed according to the Empirical Phenomenological Psychological (EPP) method. The analysis generated five main themes which were shown to create a causal chain where paths to healthy behavior contributed to a process of change which was mirrored in comprehensive distancing, which in turn facilitated a reduced tendency of illnessidentity and the acquiring of new proficiencies which could be generalized to different situations in daily life which led to insights about healthier behavior.

\section{Keywords}

Cognitive Behavior Therapy, Depression, Healthy Behavior, MBCT, Mindfulness

\section{Introduction}

Interest in mindfulness has increased dramatically in the past decade and is now a standard part of the treatment

\footnotetext{
"Corresponding author.
}

How to cite this paper: Ingvarsson, T., Nordén, T. and Norlander, T. (2014) Mindfulness-Based Cognitive Therapy: A Case Study on Experiences of Healthy Behaviors by Clients in Psychiatric Care. Open Journal of Medical Psychology, 3, $390-402$. http://dx.doi.org/10.4236/ojmp.2014.35041 
provided at health-care and psychiatric clinics [1]. The third wave of cognitive behavioral therapy comprises several forms of treatment which include attention-training as part of a broader treatment approach, for example Mindfulness-Based Stress Reduction [2] or Meta Cognitive Therapy and Dialectical Behavior Therapy [3]. One form of treatment, where attention and awareness of one's experience of the present play a central role, is Mindfulness-Based Cognitive Therapy (MBCT) [4]. In MBCT, mindfulness is defined as a focus on the present moment, calmly observing one's own thoughts, sensations and emotions and observing and accepting them without judgment [4]. Healthy behaviors are defined in the study as those which aim to improve the individual's wellbeing and physical function [5]. A healthy behavior is considered incompatible with depressive behaviors. The definition of unhealthy behaviors, then, is those behaviors that do not promote improvements in well-being and physical function.

MBCT is a psychological therapy group treatment which was developed in order to prevent relapse of clinical depression [4]. However, research has shown that MBCT is also suitable for individuals with chronic depressions [6]. According to the cognitive view, individuals suffering from depression have negative thoughts about themselves, their experiences and their future, which perpetuate issues of depression [7]. For this reason, the challenge facing the developers of MBCT was to acquire further understanding of the mechanisms behind recurrent depression. Two themes were focused on the differential activation hypothesis and rumination [4]. The differential activation hypothesis suggested that a melancholic state of mind could arouse negative thought patterns that the individuals had had in previous depressive episodes. According to the hypothesis, one contributing factor for relapse in depression was the connection between a melancholic state of mind and negative thought patterns, and this system of interactions can easily be established [8]. An early extensive review of the research concerning cognitive vulnerability to unipolar depression [9] supports such a hypothesis. The review showed that individuals suffering from depression were more likely to be caught up in negative thought patterns when they found themselves in a negative frame of mind. Also, individuals with recurring depressions became increasingly prone to new illness, while external stress played a diminishing role as the deciding factor [10]. Post and colleagues called this process "kindling" [11] and several later studies supported the existence of such a mechanism [12]. Rumination, the excessive and repeated analyzing of one's own situation and condition, was the other significant factor that Segal [4] emphasized. It was chiefly Nolen-Hoeksema's research on rumination [13] that inspired the developers of MBCT, where it became apparent that individuals that were prone to ruminate in order to come to terms with depressive symptoms actually worsened their depression over time and that rumination not only foreshadows depression but predicts the severity of the case.

A great deal of quantitative research has also been devoted to MBCT and its effect regarding the prevention of a relapse of depression. In a study now considered a classic mindfulness study [14] 145 patients with two or several episodes of major depression were given either treatment as usual or treatment as usual including MBCT. The treatment as usual involved treatment without either CBT or medical treatment. The patients were not suffering from depression at the start of treatment. The patients were followed up for a period of 14 months, and the result was that the risk of relapse for the patients who had only the usual CBT was $67 \%$, but only $37 \%$ for those who also received MBCT. It was important to note that there was no difference in the frequency of recurrence between the focus group and those having received MBCT treatment [14]. The study was replicated by $\mathrm{Ma}$ and Teasdale [15] and confirmed earlier results. In later years, several systematic reviews and meta-analyses had been carried out in this field. A meta-analysis conducted by Piet and Hougaard [16] showed that MBCT reduced the risk for relapse by $34 \%$ for individuals that had had three or more episodes. In the meta-analysis, 6 randomized studies were included in all 594 patients participating in. Another meta-analysis showed only a moderate effect size regarding the ability of MBCT to prevent relapse [17]. An additional systematic review of MBCT studies also showed a moderate effect size [6]. The central role that MBCT has played so far is the prevention of depression [6]. However, studies on other groups have been carried out. One study [12] investigated the effect of mindfulness on therapy-refractory patients. In a randomized control study [18] it was found that the effects of MBCT were mediated by increased mindfulness and compassion. It was also found that the association between increased cognitive reactivity and poorer outcome disappeared for the MBKT group after treatment (which did not use antidepressants during treatment), while the relationship persisted for the control group (which was treated with anti-depressant medication).

To date, research into mindfulness and healthy behaviors indicates that there is a correlation between these variables. Individuals who acted "in mindful awareness" also acted in greater accordance with their values and interests [19]. In another study, it became clear that the patients were more prone to pursue meaningful activities 
and relationships after undergoing MBCT [20]. There are qualitative studies that have examined how MBCT is seen by individuals suffering from depressions. Finucane and Mercer [21] concluded that MBCT was found to be helpful for the majority of thirteen patients with recurring depression who were interviewed three months after treatment. Allen, Bromley, Kuyken and Sonnenberg [22] interviewed twenty patients with depression in partial or full remission twelve months after MBCT. Four themes emerged: control, acceptance, relationships and resistance. Bailie, Kuyken and Sonnenberg [23] examined how MBCT affected parenthood for 16 individuals with recurring depressions. Results showed that the practice of mindfulness influenced the patterns of interaction with children, that is, parents could better handle negative feelings and they could more readily take the point of view of the children, and also became more aware of their own needs. Another study [24] found that MBCT was helpful in dealing with OCD- and OCD-related problems where two thirds of the participants reported alleviation from the symptoms of OCD. Mason and Hargreaves [25] found in a qualitative study that the development of mindfulness skills provided the core of the therapeutic process.

In summary, there is today a great body of quantitative studies as well as a lesser number of qualitative studies on the effects of MBCT. Significant symptom reduction has been reported after participation so far, but MBCT has mainly shown its importance in preventing relapses in depression. There is research indicating that individuals who find themselves in a "mindful" state tend to develop healthier behaviors. There are also indications that MBCT participants share that tendency. However, it has not been possible to find neither quantitative nor qualitative studies that specifically study the healthy behaviors and their development in connection with participation in MBCT. The purpose of this study was for the first time to investigate the patients' own experience of developing healthy behavior in connection with their participation in MBCT.

\section{Method}

\subsection{Design}

Between eight and ten individuals take part in an MBCT group [4]. They convene during eight weeks to practice meditation exercises as a way of training mindfulness. The various formal exercises routines, such as Body Scan, Mindful Yoga, Stretch and Breath, Sitting Meditation and Three Minutes' Breathing Space, are in different ways intended to help the individual to develop awareness in the present. After each exercise, a moment is provided for the participant's reflection on the experience of practicing the exercise. Each week there is a theme related to CBT and/or eastern meditation tradition. For example, it can be concerned with the roll of thought processes during depression. These psychoeducational aspects comprise only a small part of the treatment, since the focus lies on mindfulness exercises and open discussion about the experiences they give. The participants then do their mindfulness-training at home on a daily basis, between 30 - 40 minutes. In the current study, the criteria for inclusion was men and women, eighteen years or older, that suffered from recurrent unipolar or bipolar depression. There were to have had at least two depressions, but for participation in MBCT, the depression had to be in remittal. The treatment was not available for emotionally unstable personality disorder, anorexia, ongoing manic episode, psychotic depression, obsessive compulsive disorder, addiction and ADHD.

\subsection{Ethical Considerations}

The present study followed the ethical standards of the World Medical Association declaration of Helsinki concerning the Ethical Principles of Medical Research involving human subjects. The survey was implemented as part of the psychiatric clinic's internal evaluation. The data were gathered by a student in the Psychotherapy program at the Evidens University College and constituted the basis for an examination thesis. A contract was drawn up where the participating patients were informed that written reports would be formulated such that anonymity would be maintained. In addition, each patient was informed of his or her right to break off participation in the training project at any time without needing to give a reason. Given these conditions, the Swedish rules on ethics allow those responsible for a training program to compile student reports to create an article.

\subsection{Participants}

Two participants were asked after completed treatment whether they were willing to take part in a study about their experiences of behavioral changes in connection with their participation in group treatment according to Mindfulness-Based Cognitive Therapy (MBCT). The selection took place by a random procedure, and the first 
two that were asked accepted to take part in the study. One of the participants was a 34-year-old woman with a diagnosed bipolar illness. The woman lived with her nine-year-old daughter and was unemployed but took part in vocational training. She had had contact person at a psychiatric clinic for many years, but had never been in any kind of psychotherapy. The other participant, a woman of 58 years, had had recurrent depressive episodes but no manic or hypomanic relapses. The woman had chronic fatigue syndrome which did not improve despite long sick leave and earlier conversational counselling with psychodynamic focus. She was on sick leave for the duration of the course. The woman lived with her husband and has two grown children who no longer live at home. These two patients who participated will be referred to as respondents.

\subsection{Procedure}

Patients for group treatment were recruited at an average-sized psychiatric clinic in southern Sweden. Those patients who according to health care providers satisfied the criteria for inclusion (see the section Design) were informed about mindfulness group treatment and could then register their interest in participating. The patients were then called to an interview for final assessment in regard to eligibility to contribute to the group treatment. Nine of ten patients completed the MBCT treatment and one withdrew after the first meeting. Absence was low; throughout the eight sessions, only four absences were registered. No one particular participant stood out statistically. All patients in the group treatment were women, since no men had registered their interest in contributing.

The treatment was based on the manual "Mindfulness-based Cognitive Therapy for Depression" [4] and the group convened eight times during a period of four months. Each session was two hours long, with an added fifteen-minute break. A half-day retreat was arranged in conjunction with the course involving a three hour meeting of the patients who in conjunction with the course which involved mindfulness exercises, practiced in silence and with short, fifteen-minute breaks for contemplation. After two and four months respectively, evaluation sessions were carried out. The treatment was conducted by two registered psychologists who worked with $\mathrm{CBT}$ as their point of departure. One of them was a registered psychotherapist and the other was a trained instructor in Mindfulness. Both instructors were experienced at working with, and taking part in, MBCT treatment groups. One of them had also taken part in week-long retreats on several occasions.

About four weeks after the last treatment, times were slated for interviews. Interviews were performed by one of the mindfulness instructors. The interviews lasted sixty minutes and both were recorded. The respondents shared their views of what changes they experienced during the course of the treatment in a semi structured interview. In an open initial question, the respondent could share thoughts of mindfulness in daily life. Other possible questions could be those dealing with life before and after taking part in the mindfulness course, or how daily life was affected when mindfulness training began. The purpose of the questions was to tease out the respondent's story with regard to changes in behavior. For this, the first question was sufficient. The interviewer then encouraged the respondent to develop and deepen their account of these changes of behavior and how they had developed during the course.

\subsection{Data Analysis}

The data analysis was run according to the Empirical Phenomenological Psychological (EPP) method devised by Karlsson [26] where the analyses is done in five different steps. First, the material is read through several times in order to get a basic understanding of it. Second, the text is analyzed and broken up into smaller units, so-called "meaning-units" (MU) which do not follow grammatical rules but are limited when the content is given a new meaning. Third, each meaning unit is transformed into abstract terms which capture its original context. For example, a meaning unit which reads "I was experiencing some physical anxiety. I am more aware of how my body feels now. I recognize it instantly..." becomes "The participant describes a heightened physical awareness after taking part in MBCT".

Fourth, MUs are synthesized into situated structures depending on which phenomenon they describe. This step generated 24 categories, each of which was summarized in a shorter text, a so-called synopsis, and a headline. To control for the reliability of the results in the fourth step, the Norlander Credibility Test (NCT) devised for phenomenological analyses was used [27]-[29]. The test was conducted so that 10 of the 24 categories were selected at random. Of these, five of the transformed "meaning units" were drawn at random from each category. The material was then given to two mutually independent assessors and their purpose was to distribute the fifty meaning units among the ten synopses. One assessor found $76 \%$ agreement with the categorization in the analy- 
sis and the other found $74 \%$ agreement. This gave a total NCT-value of 75 , a level comparable to earlier studies [29].

Finally, during the fifth stage, categories were developed into typological structures that describe the concentrated essence of the phenomenon being studied. In the present study, the "first author" read through the synopses several times to get an overall picture of the data presented, in order to gather it into five different aspects. The two other authors each did a critical examination of this solution and tried to find other candidates for the theme but concluded that the original proposal best described the essence of the study. The authors were also able to jointly observe that the five themes described the development of healthy behaviors related to mindfulness training as a chain of cause and effect. An overview of the categories and spread of meaning units on the themes are given in Table 1.

\section{Results and Discussion}

As mentioned, the twenty-four synopses were grouped into five main themes. These were (a) Roads to healthy behaviors, (b) Comprehensive distancing, (c) Acquiring new proficiencies, (d) Generalizing and (e) Healthy behavior and the nature thereof. The five were shown to create a causal chain where healthy behavior contributes to a process of change which is mirrored in comprehensive distancing, which in turn facilitates a reduced tendency to illness-identity and the acquiring of new proficiencies which can be generalized to different situations in daily life which lead to insights about healthier behavior. Below, the themes and their interrelation are discussed. The examples of the MUs given in italics are the original MUs. Thus, they are not the ones that were altered, which were only used in the analysis.

\section{Paths to Healthier Behaviors}

The respondents describe how they acquire new insights, "eureka moments", when they are given the opportunity to observe their mind and themselves, rather than taking in knowledge from others. The individual learns how the mind works, and how one relates to the inner and outer environment, through training "I would not have

Table 1. Overview: Themes, with number of Meaning Units (MUs) and Categories.

\begin{tabular}{|c|c|}
\hline Themes & Categories \\
\hline $\begin{array}{l}\text { Paths to healthier behaviors } \\
\text { (40 MUs) }\end{array}$ & $\begin{array}{l}\text { 1. The importance of practical exercises for change. } \\
\text { 2. Intellectual understanding is a first step towards change. } \\
\text { 3. The acquisition of something new or the acquisition of a skill lost_- different starting points. } \\
\text { 4. The group format - sharing experiences contributes to community and inspiration. }\end{array}$ \\
\hline $\begin{array}{l}\text { Distancing } \\
\text { (45 MUs) }\end{array}$ & $\begin{array}{l}\text { 5. An increased body awareness. } \\
\text { 6. Mindfulness leads to relaxation in the body and the mind. } \\
\text { 7. An increased understanding of the disorder. } \\
\text { 8. Increased insight into the nature of the mind. } \\
\text { 9. An increased insight into behavior and its consequences. }\end{array}$ \\
\hline $\begin{array}{l}\text { Acquisition of new skills } \\
\text { (79 MUs) }\end{array}$ & $\begin{array}{l}\text { 10. Using the signals of the body as a guide. } \\
\text { 11. Using breathing to go into conscious presence. } \\
\text { 12. Conducting a helpful internal dialogue with oneself. } \\
\text { 13. Allowing difficult internal experiences. } \\
\text { 14. Having an accepting attitude beyond "right" and "wrong". } \\
\text { 15. The different approaches to thoughts. } \\
\text { 16. Slowing down. }\end{array}$ \\
\hline $\begin{array}{l}\text { Generalization } \\
\text { ( } 81 \text { MUs) }\end{array}$ & $\begin{array}{l}\text { 17. The conscious presence spreads automatically to everyday life. } \\
\text { 18. Making active choices in everyday life. } \\
\text { 19. Being guided by what is important in life. }\end{array}$ \\
\hline $\begin{array}{l}\text { Healthy behaviors and their nature } \\
\text { (47 MUs) }\end{array}$ & $\begin{array}{l}\text { 20. Prioritizing oneself and setting boundaries against the world around. } \\
\text { 21. Meeting setbacks with an accepting and friendly attitude. } \\
\text { 22. Treating oneself as valuable. } \\
\text { 23. Getting involved in the small instances of pleasure in everyday life. } \\
\text { 24. Having relationships characterized by openness and acceptance. }\end{array}$ \\
\hline
\end{tabular}


realized that emotions would pass without lots and lots of training". The repetitive training in mindfulness contributed to greater composure on the part of the respondents, who also began to reach levels of important insight. Another road that the respondents described was the importance of intellectual understanding which in this case meant that finding out about mindfulness was something of an eye-opener, or rather a reminder, that the phenomenon actually existed: “...that I know from mindfulness that it is important to confront things, you know. We talked about that and I think about it". The periodic meetings in the group afforded members an important opportunity to share their experiences, thus providing inspiration as well as a feeling of community. When the respondents openly shared their personal experiences, it helped them feel more human and less alone: "It made me happy that so many talked about trust and comfort. Being together...the fact that no one would say anything at first, but then they got to talking so much that you couldn't get a word in edgewise. And this sharing made you feel human. We were all in it together, so to speak".

In summary, the respondents saw their own mindfulness training as the key to change, even if knowledge of others' experience could spark one's own development. Also, the particular format of working within a group supported and contributed to creating insight, inspiration and a sense of community. In closing, it is important to note that the respondents had different points of departure at the outset of the group treatment. One of the participants reported that she had had access to certain aspects of mindfulness without being aware of it, while mindfulness was both practically and theoretically unknown to the other at the start. The respondents' stories indicate that the different points of departure figured significantly during the course of the training. The woman who had always had a good faculty for taking in her surroundings through the senses was reminded of this quality. During the course, she developed this sensory clarity, so that she could choose to pursue the satisfaction of finding everyday enjoyment. For the other woman, mindfulness was like learning a foreign language. Training routines in mindfulness meant initial resistance, fears and thoughts of "not getting it right". Yet, she began her journey from her unique point of departure and was able to discover, for example, when her fears would have her flee.

\section{Distancing}

After having practiced mindfulness regularly, the respondents became more aware of their body and its signals. One participant for the first time became aware of having a body, "I have acquired a body while practicing mindfulness. Everything from the head down is new to me, I could say. I never paid attention to it before". Furthermore, the respondents described how the signals from the body may appear "automatically", without the body being the focus of attention. Awareness of the body and its signals may give the individual the ability to make constructive choices about what is to happen next, "I feel stress in the body and I try to find a way of calming down. If I breathe, I often feel calmer". The respondents reported feeling greater relaxation when they were in a state of mindfulness. It is not just a sense of physical relaxation, but the respondents described a kind of relaxation comprising both the physical and the mental dimension. The respondents experience that total relaxation that leads to a greater internal space. The respondents report experiences of the opposite, i.e. the belief that "something ought to be, or be done, differently", led to feelings of tension. It is possible then that the result is a feeling of a reduced space. In the relaxed space, the respondents achieve a greater perspective on their internal experiences and also perceive greater possibilities in the situation, "when I become more relaxed, it is like getting more space to think more clearly and giving the thoughts less space and importance, if I want that to happen".

It is interesting to note that a mindful approach, at first in a formal exercise and later more and more in daily life, the approach helped the respondents to view certain thoughts, behaviors, and feelings as belonging to a disorder and not something that characterized the individuals, themselves. Observing oneself in a mindful way, and repeatedly seeing how e.g., certain thoughts reappeared along with feeling worse, contributed to a greater awareness of their disorder and its nature. A mindful approach contributed to a greater acceptance of the disorder, "now I pay attention to external signs of how I am feeling worse and I understand that my thoughts of feeling worthless have to do with the disorder". An increased awareness of and insight into the disorder and its characteristics appeared to help the respondents make constructive choices "first I stop and then I think. Why am I doing this now? Oh yes, I have this disorder. That may be the reason. I am more aware of my problems now and the fact that things get worse if I get stressed out". The respondents describe an increased ability to identify and name feelings, as well as describe how they manifest themselves physically. They also have a greater insight in- 
to the nature of thought, and how thoughts and emotions are connected. The respondents themselves put into words the importance of acknowledging their feelings in order to be able to make constructive choices. Exploring the characteristics of feelings and thoughts leads to an increase in insights. It is also clear that knowledge of the mind and its nature provides a perspective on these phenomena, "and now I know, after a great deal of practice, that I usually experience anxiety for a long time, it just comes a bit. One squeeze and it passes after a while. It gives me a perspective. It gives me a perspective on the problem. I remind myself of that". The respondents described how, through their own experience, i.e. regular mindfulness practice, they acquired a perspective on internal and external events. Total relaxation and insights about the nature of the mind as well as alternate approaches to life led the individuals to acquire a perspective.

\section{Acquisition of New Skills}

The respondents learned that through contact with their body can acquire knowledge about their needs, wishes, and boundaries. The intellectual knowledge that it is possible e.g., to create boundaries has existed beforehand, but what is new is allowing the body and its signals to guide you to know when it is time to quit. The body also contains memories, both positive and negative, which may come to life when one pays attention to the body. Those memories can guide an individual regarding what is healthy or not healthy in the here and now. "Every Friday it is 'Body balance' and it involves static postures which involve stretching and bending backwards. The whole time I feel the movements, the breathing...they make the body feel good and I get stronger. That's when I remember my training from before and it is...ahh...remembering from the past. I want more of that". Both respondents talk about the breathing being an important starting point, and both respondents use the expression "finding your way home" in terms of the role of breathing when it comes to placing it in the here and now. They make a conscious choice to focus on their breathing when they become aware that the situation may be difficult or taxing, "first you must come home by breathing and being in the body, and then you become more aware of what to do". The effects are calm, clearer thoughts and a greater possibility of coming into contact with what is the next helpful step. Such a step may be an internal dialogue. The respondents report that a new internal dialogue takes shape following participation in the mindfulness course. Earlier self-critical thoughts and worries dominated, but now the respondents use their internal voice to a greater extent in order to guide themselves to make choices that are constructive and long term. The internal dialogue has certain characteristics. It is friendly and accepting, both toward the individual herself and the situation, it contains logical thinking, and the individual reminds herself of her long term goals, "I reasoned with myself and said to myself that I will do what I can and I will do the best I can. Like in a friendly way, and I ask myself what might actually happen. I was calmer by reasoning that way".

The respondents report that they do not get lost in difficult internal experiences any more. Feelings and thoughts which automatically appear in a situation, no longer determine the direction without thought. The respondents report how they execute what they have decided to do, despite the fact that the situation elicits discomfort. They start by becoming aware that strong feelings and thoughts are present. The strong internal experiences are then allowed to be part of the situation, but they may not take over and decide on the direction, "and the anxiety...yes, it can follow me and be with me, but I am among people. I could feel that you wanted to come along, so I suppose you can. Then I suppose I must sit here and feel a bit bad, but I can at least have some cof$f e$ ". A breakthrough for both the respondents was an insight that in mindfulness not much is either right or wrong. There is no right or wrong way of doing the exercises, there are no better or worse experiences of reporting etc., "When you feel bad and worthless doing it at home, then one would realize that others did it their way, and one understood that there was nothing that was right or wrong". That notion helped the respondents find alternate ways of handling their situations instead of giving up or avoid the situation. The respondents felt listened to regarding their development, their unique ways of handling a situation. That approach contributed to fewer feelings of guilt and self-criticism. The insight was achieved by way of exercises, the curious and open stance of the leaders and that of the other participants in sharing of experiences and of making an exception from "the rules" and of receiving acceptance for their behavior. The respondents then started to experiment with such an attitude in their daily life. It also makes for a more accepting space for how to deal with one's thoughts: to stop thinking of a topic when it is not helpful, to question them, and to find other perspectives, and to allow the thoughts to be there without becoming involved in their content. The respondents now use those approaches in situations of daily life and they report a greater calm and security as a result of that approach. The approach also 
contributes to their ability to make a constructive choice in their next step "I know what my perspective is and I think that it is her lack of knowledge that makes her upset, and I become calm and secure with my choice, since I don't fly away in my thought, and then I can choose something good". The respondents told about how they have slowed down their pace after participating in the course. They report that the slower pace makes them able to be in touch with their body, a fact that can affect them in such a way as to make more constructive choices, rather than becoming stressed into something when they do not have contact with their inner world, "What I learned in the course was to do things at a slow pace. The body can then follow and it helps you to make choices".

\section{Generalization}

The respondents achieved a perspective on internal and external events. They learned skills with roots in mindfulness, and eventually mindfulness would emerge "automatically" in daily life, "on one mindfulness occasion, you told us to confront the anxiety instead of fleeing and now I did just that in the cafeteria, and talked to myself in that way without being aware of the fact that that is what we had practiced in the course". The respondents even initially received small exercises, e.g., doing an everyday activity in a state of mindfulness although very few active interventions were intended directly to create expectations in daily life. The respondents practice mindfulness without goals, and the only thing they had to do was over and over to bring their attention back to the here and now. The respondents described how they in connection with practice suddenly gained an insight into the nature of thoughts, or what acceptance really meant. The respondents described how they in daily life suddenly used skills they had acquired in the MBCT group. In addition to the fact that mindfulness automatically generalized to everyday life, the respondents more often began consciously to make choices in daily life based on what was healthy and constructive for her, "I have realized that I can choose and I can handle a lot more today and I can choose not to select out environments where it is too much". The respondents acquired the insight during treatment that it is possible to choose, in many more situations, than they had previously thought.

The respondents once again came back to the body as their guide for what were more or less healthy choices in a given situation. The respondents, before the course, had had an approach to the body as less thought through; they had ignored bodily signals, or the opposite, they overreacted to bodily signals. An example of the former was the woman who continued to work although her body asked her to stop, and an example of the latter was the woman who left her work place when she felt her heart racing and breathing difficulties although her body asked her to stop. While in contact with their body the respondents could more easily decide if a situation was good for her or not, but during the course they had also become more aware of their values and were able to start using them to find their orientation in the here and now. "What rings internally is a bit like electricity on the inside. It resonates to what suits you and you choose what suits you and what is closest to you". Following treatment the respondents were more aware of old, unhealthy patterns of behavior and their consequences, while also increasing their awareness of what was important in life and what was more healthy in the long term. A greater awareness of what was important in life, they developed through both a greater awareness about the negative consequences of earlier behaviors and through getting in touch with the present moment in complete, conscious presence. The respondents had had the experience of having lost their direction in life when they were too preoccupied with thoughts and powerful emotions.

\section{Healthy Behaviors and Their Nature}

The respondents reported healthy behaviors which they developed through the course of the treatment. It was both about behaviors which were unknown before the onset of the course and behaviors which had been there all along but had been absent for some time for various reasons. The new or semi-new behaviors were characterized by the notion that they corresponded to the long term goals and values of the respondent. Through their participation in MBCT, the respondents came into contact with values which dealt with prioritizing their own wellbeing and relationships with their near and dear. They also reported behavioral changes such as making active choices in that direction. The relationships with others and with themselves looked different following the MBCT course were characterized by a greater openness, acceptance, and compassion. "I say to my daughter when she messes up: As long as you try, as long as you do the best you can. I feel like I am saying something good, as a mother, for once and that she gets something positive out of it. Previously, I just got angry and completely lost my temper". 
The respondents reported that they treated themselves as valuable and they prioritized themselves and created boundaries vis à vis others, "I accept who I am and that I am who I am, that I am valuable and if others cannot do that, so be it. I become more proud of myself for the small things I can do rather than what failed. Earlier I thought that I was worthless and I got stuck in that idea and my failures". They had also developed their relationships with others and the relationships were now characterized by a greater openness and acceptance. The respondents were more open and more tolerant vis à vis the world around them. And other people began to treat them with greater respect and acceptance. An interesting example is the woman who said that her daughter had only now had the courage to invite friends over. Earlier she had been ashamed of the lack of order at home, but now she had the courage to invite friends after talking with her mother about the disorder. The woman herself thought that the change was due to the fact that she herself had accepted her disorder and that she could now be open about it. As a result the daughter was then able to deal with the situation differently.

The respondents also reported other changes of behavior which were on a par with their values, e.g., giving the small moments in everyday life more space and dealing with setbacks in life with greater acceptance and more acceptance vis-á-vis themselves and their situation, "I feel like I am saying something good, like mother for once, gets something positive from. Earlier I only got angry and lost my temper completely". It is interesting to note tht the values that became clear and the healthy behaviors that were given more space during the course of treatment were easily in accordance with mindfulness and the attitudes that go with it. Here we have mindfulness; the specific attentions with its attitude of acceptance and its intention of compassion have traveled all the way from the formal exercise and into the individual's everyday life.

\section{The Results in Conjunction with Previous Research}

A new meta level with five related themes crystallized when the five steps of analysis were done in accordance with the EPP-method [26]. The themes illustrated the experiences of two individuals following participation in MBCT. The themes provided knowledge of different paths toward change, and what those paths might look like as well as knowledge about characteristics of the behaviors that developed. In the section below the results of the study will be anchored in theories and current research.

To date there is an inconsistency regarding to what extent mindfulness is responsible for changes which occur in connection with participation in mindfulness-based group treatments [30]. For example it is not clear what the role is of non-specific factors e.g., social support plays. Two randomized control studies, however, indicated that mindfulness contributed to changes and positive effects on health following participation in mindfulness (MBCT) [31] [32]. The current study indicated that it was the participants' own experiences in connection with the practice of mindfulness that comprised the most important path toward healthy behaviors.

The current study also showed that the group format contributed to the participants' feelings of security, community, and of less loneliness regarding their problems. This notion is in accordance with previous research [33]. An earlier, qualitative study showed that the group played different roles in Behavioral activation (BA), and in MBCT, respectively. In BA, the respondents noted above all that they felt that the group provided a "lift" and energy. In contrast the MBCT-patients noted that the group had a motivating role in the patients' own work; the group motivated them to do the exercises during the sessions and at home. [20]. The current study as well the respondents reported that the experiences and progress of the others motivated them towards continued practice.

The respondents described how they experienced a total relaxation after a while through practical exercises in mindfulness. They described the relaxation as a "greater space" which provided a perspective. Chambers, Gullone and Allen [34] list relaxation as one of the most discussed processes in connection with mindfulness. In the West relaxation in connection with mindfulness has been described as a possible by-product and not as a goal in itself. Segal and associates [4] are clear about the fact that exercises in mindfulness do not have as their goal to achieve a relaxed state and Baer [35] described relaxation as a positive side effect, while dismissing it as an important process in mindfulness. It is interesting against that background to note that the Buddhist literature de facto emphasizes that relaxation is an important state closely tied to meditation [36]. The Buddhist literature does not argue as in the West, that relaxation is mainly a bodily relaxation but a "relaxation of the mind". There are also Western researchers and theoreticians who believe in a broader definition of relaxation. Nyklicek [30] described relaxation as a direct effect in the practice of mindfulness. A relaxation of the whole "mind-body" system is the result when the individual accepts reality the way it is and let go of potentially disturbing thoughts 
and other mental phenomena. Blackledge and Hayes [37] seem to describe something similar when talking about the consequences of accepting emotional experiences. They argued that it leads to relaxation of emotions and an opportunity for greater space in life. Those descriptions of relaxation as something more than a physical phenomenon are in line with the descriptions provided by the respondents in the current study.

Teasdale [38] differentiates between metacognitive knowledge and metacognitive insights. The former involves the idea that the individual knows that thoughts are not always facts, and that the individual perceives thoughts as phenomena in the area of consciousness. According to Teasdale the practice of mindfulness leads to a metacognitive insight, i.e. thoughts are perceived as events in consciousness. A metacognitive insight changes the relation of the individual to the thoughts [39] suggest that "reperceiving" is like a central mechanism in mindfulness "reperceiving" involves a shift of perspectives in which the individual ceases to identify him/herself in relation to the contents of consciousness, e.g., his/her thoughts. Several other "third force" forms of therapy describe a similar process. Meta Cognitive Terapi (MCT) calls it "detached mindfulness" [40] and Relation Frame Theory (RFT) calls it "cognitivedefusion" [41].

During the time of the course the respondents learned different approaches to internal and external events. For example the respondents learned to stay and live through difficult emotions just as they appeared, they learned to keep a perspective on their thoughts, they learned how to view their own unique experience instead of relating it to what is right or wrong, and they learned how to carry on a friendly, internal dialogue with themselves. Mason and Hargreaves [25] noted the development of skills as a central mechanism in the process of change. In their study, skills mainly comprised ways to master the formal exercises such as breathing and stretching, among others, whereas "skills" in the current study comprised the development of new approaches to internal and external events. Those approaches developed when the respondent practiced an exercise over and over again, e.g., breathing. Blackledge and Hayes [37] emphasized that it is not the emotions themselves which are to be viewed as a problem, but instead how we deal with the thoughts and impulses to act that follow the emotions. Experiential avoidance of various kinds, instead of approaching and staying put in the uncomfortable feeling is what maintains the vicious cycle.

In the current study there are several examples of the respondents learning how to re-evaluate their knowledge. One such example is the respondent who, after some time in the course, viewed her anxiety as no longer dangerous. Researchers and theoreticians have different beliefs about whether cognitive restructuring takes place in mindfulness. According to Kabat-Zinn [2] no active re-evaluation or "reappraisal" takes place. In mindfulness, the issue is to be mindful of the values that appear and then to let go of them. Nyklicek [30] argues against this idea and believes that of course there is a reappraisal of thoughts, feelings, and etcetera in connection with the practice of mindfulness. Therefore a reappraisal of prior knowledge is to be seen as an important part of the process of change Nyklicek argued that the individual will re-evaluate his/her experiences and later either find new, more healthy values, or approach the situation at a meta level and let go of the actual values. The current study appears to support the Nykliceks hypothesis.

In the current study it was also clear that the respondents started to challenge a self-critical internal dialogue, characterized by friendliness and acceptance. The respondents made use of that skill in connection with the exercises and later ever more in their daily life, e.g., when dealing with setbacks or when motivating themselves to do something challenging. In an article, Feldman and Kuyken [42] described the central role of the skill that "compassion" has in MBCT. In another article Leary, Tate, Adams, Allen and Hancock [43] summarize five studies on "compassion". They concluded that "compassion" was a helpful way of handling negative thoughts and feelings, e.g., shame. To date there is a type of therapy, Compassion Based Therapy, whose purpose is to help the individual develop a warm and friendly internal dialogue which will protect against attacks on the self and negative affect such as shame and melancholy [44].

The current study showed that mindfulness was gradually generalized to everyday life in various ways. It took place both "automatically" and in a more conscious way. In the beginning of the MBCT treatment the respondents struggled with all sorts of things: the approach if they did the right thing, the pain, the purpose of the course etc. at a more conscious level. In the beginning of treatment it was a conscious act to meditate in order to practice mindfulness, but over time the respondents could sometimes feel that mindfulness became more automatic and less of an effort. That finding is in line with reports from experienced practicians of mindfulness who perceived meditation as an initially both taxing and conscious process but one that with more practice became less taxing and more automated [45]. Cognitive and neurobiological research also confirms that certain attentional processes can become automated through practice [46] [47]. That particular research was however done 
on individuals who had practiced more than 10,000 hours or individuals who participated in intensive retreats. Thus, the results are not generalizable to the current study, but there are indications that an automatization effect may take place even after participation in MBCT which is a somewhat intensive treatment.

Both Brown and Ryan [19] Nyklicek [30] propose that distancing is important for the individual to be able to act in accordance with his/her values. The respondents of the current study had become more aware of their existing choices following the course. They had come into contact with what was important in life during the course of treatment and they began to guide themselves from the perspective of that insight. They confirmed the importance of conscious presence, being undisturbed by disorganized thoughts and they were more conscious of destructive behaviors in order to perceive what was healthy and more long term for themselves. They described how they stopped short and considered what they wanted before making their choices. The respondents also spoke emphatically about the importance of the body as a guide to learning how to distinguish between the healthy and the unhealthy. The importance of the body in the process of change has been given limited attention [25] [30] [39].

\section{Future Research}

Research into the complex process of change in mindfulness is still relatively young and more research is needed [30]. The current study showed that the process of change could be illustrated in the form of a causal chain. Perhaps that causal chain constitutes a "main road" to change, but continued research into the processes and partial processes may provide additional knowledge about the interaction among different factors in that process of change. For example, further research into the connection between mindfulness and relaxation and between mindfulness and meta-cognitive insights in controlled studies is called. Are those effects of mindfulness to be interpreted as suggested by Nyklicek [30] in his model? The current study supported such a hypothesis, but future experiments will show if this is the case. Are there possibly other direct effects of mindfulness, not revealed in the current study? Nyklicek [30] for example suggested "harmony" and "contact" as direct effects of mindfulness. The results of the current study also showed that the type of relaxation mentioned by the respondents was of a kind that comprised the entire "mind-body-system". Continued research into the characteristics of relaxation and their role ought to be relevant. In the study it was also found that an increased body awareness and the possibility of using the body as a guide played an important role in the process of change. The important role of the body in the process of change is an area which deserves greater space in future research. The current study showed that personal experiences of mindfulness, in the form of regularly performed exercises, were by far the most important for a process of change to take place. Future research might therefore examine what extent the practice of mindfulness plays a role for mental well-being in connection with participation in MBCT. Finally, there are several possible associations between mindfulness and attachment which deserve to be examined. For example there are indications that a secure attachment is correlated with mindfulness, and the two phenomena appear to give rise to comparable healthy effects. It is both interesting and hopeful to think that mindfulness might constitute a possible road to acquired attachment later in life.

\section{References}

[1] Plank, K. (2012) Modernamyterom Mindfulness [Modern Myths of Mindfulness]. Läkartidningen, 43, 1968-1970.

[2] Kabat-Zinn, J. (2003) Mindfulness-Based Interventions in Context: Past, Present, and Future. Clinical Psychology: Science and Practice, 10, 144-156. http://dx.doi.org/10.1093/clipsy.bpg016

[3] Kahl, K.G., Winter, L., Schweiger, U. and Sipos, V. (2011) The Third Wave of Cognitive-Behavioral Psychotherapies: Concepts and Efficacy. Fortschritte der Neurologie-Psychiatrie, 79, 330-339. http://dx.doi.org/10.1055/s-0029-1245963

[4] Segal, Z.W., Williams, J.M. and Teasdale, J.D. (2002) Mindfulness-Based Cognitive Therapy for Depression. A New Approach to Preventing Relapse. The Guilford Press, New York.

[5] Hopko, D.R., Lejuez, C.W., Ruggiero, K.J. and Eifert, G.H. (2003) Contemporary Behavioral Activation Treatments for Depression: Procedures, Principles, and Progress. Clinical Psychology Review, 23, 699-717. http://dx.doi.org/10.1016/S0272-7358(03)00070-9

[6] Fjorback, L.O., Arendt, M., Örnböl, E., Fink, P. and Walach, H. (2011) Mindfulness-Based Stress Reduction and Mindfulness-Based Cognitive Therapy-A Systematic Review of Randomized Controlled Trails. Acta Psychiatrica Scandinavica, 124, 102-119. http://dx.doi.org/10.1111/j.1600-0447.2011.01704.x 
[7] Beck, A.T. and Alford, B.A. (2009) Depression Causes and Treatment. University of Pennsylvania Press, Philadelphia.

[8] Lau, M.A., Zindel, V., Segal, J. and Williams, M.G. (2004) Teasdale's Differential Activation Hypothesis: Implications for Mechanisms of Depressive Relapse and Suicidal Behavior. Behavior Research and Therapy, 42, 1001-1017. http://dx.doi.org/10.1016/j.brat.2004.03.003

[9] Segal, Z.V. and Ingram, R.E. (1994) Mood Priming and Construct Activation in Tests of Cognitive Vulnerability to Unipolar Depression. Clinical Psychology Review, 14, 663-695. http://dx.doi.org/10.1016/0272-7358(94)90003-5

[10] Post, R.M. (1992) Transduction of Psychosocial Stress into the Neurobiology of Recurrent Affective Disorder. American Journal of Psychiatry, 149, 999-1010.

[11] Post, R.M., Rubinow, D.R. and Ballenger, J.C. (1986) Conditioning and Sensitization in the Longitudinal Course of Affective Illness. British Journal of Psychiatry, 149, 191-201. http://dx.doi.org/10.1192/bjp.149.2.191

[12] Ehnvall, A. and Ågren, H. (2002) Patterns of Sensitization in the Course of Affective Illness. A Life-Charting Study of Treatment-Refractory Depressed Patients. Journal of Affective Disorders, 70, 67-75. http://dx.doi.org/10.1016/S0165-0327(01)00328-7

[13] Nolen-Hoeksema, S. (2000) The Role of Rumination in Depressive Disorders and Mixed Anxiety/Depressive Symptoms. Journal of Abnormal Psychology, 109, 504-511. http://dx.doi.org/10.1037/0021-843X.109.3.504

[14] Teasdale, J.D., Segal, Z.W., Williams, J.M., Ridgeway, V.A., Soulsby, J.M. and Lau, M.A. (2000) Prevention of Relapse/Recurrence in Major Depression by Mindfulness-Based Cognitive Therapy. Journal of Consulting and Clinical Psychology, 68, 615-623. http://dx.doi.org/10.1037/0022-006X.68.4.615

[15] Ma, S.H. and Teasdale, J.D. (2004) Mindfulness-Based Cognitive Therapy for Depression: Replication and Exploration of Differential Relapse Prevention Effects. Journal of Consulting and Clinical Psychology, 72, 31-40. http://dx.doi.org/10.1037/0022-006X.72.1.31

[16] Piet, J. and Hougaard, E. (2011) The Effect of Mindfulness-Based Cognitive Therapy for Prevention of Relapse in Recurrent Major Depressive Disorder: A Systematic Review and Meta-Analysis. Clinical Psychology Review, 31, 10321040. http://dx.doi.org/10.1016/j.cpr.2011.05.002

[17] Chiesa, A. and Serretti, A. (2010) Mindfulness Based Cognitive Therapy for Psychiatric Disorders: A Systematic Review and Meta-Analysis. Psychiatry Research, 187, 441-453. http://dx.doi.org/10.1016/j.psychres.2010.08.011

[18] Kuyken, W., Watkins, E., Holden, E., White, K., Taylor, R.S., Byford, S., Evans, A., Radford, S., Teasdale, J.D. and Dalgleish, T. (2010) How Does Mindfulness-Based Cognitive Therapy Work? Behavior Research and Therapy, 48, 1105-1112. http://dx.doi.org/10.1016/j.brat.2010.08.003

[19] Brown, K.W. and Ryan, R.M. (2003) The Benefits of Being Present: Mindfulness and Its Role in Psychological Well-Being. Journal of Personality and Social Psychology, 84, 822-848. http://dx.doi.org/10.1037/0022-3514.84.4.822

[20] Bengtsson, L. and Ödéhn, E. (2010) Experiences of Group Treatments Behavioral Activation and Mindfulness-Based Cognitive Therapy for Intractable Depression. Göteborg University, Göteborg.

[21] Finucane, A. and Mercer, S.W. (2006) An Exploratory Mixed Methods Study of the Acceptability and Effectiveness of Mindfulness-Based Cognitive Therapy for Patients with Active Depression and Anxiety in Primary Care. BMC Psychiatry, 6, 14. http://dx.doi.org/10.1186/1471-244X-6-14

[22] Allen, M., Bromley, A., Kuyken, W. and Sonnenberg, S.J. (2009) Participants' Experiences of Mindfulness-Based Cognitive Therapy: "It Changed Me in Just about Every Way Possible". Behavioural and Cognitive Psychotherapy, 37, 413-430. http://dx.doi.org/10.1017/S135246580999004X

[23] Bailie, C., Kuyken, W. and Sonnenberg, S. (2012) The Experience of Parents in Mindfulness-Based Cognitive Therapy. Clinical Child Psychology and Psychiatry, 17, 103-119. http://dx.doi.org/10.1177/1359104510392296

[24] Hertenstein, E., Rose, N., Voderholzer, U., Heidenreich, T., Nissen, C., Thiel, N., Herbst, N. and Kulz, A.K. (2012) Mindfulness-Based Cognitive Therapy in Obsessive-Compulsive Disorder-A Qualitative Study Concerning Patients' Experience. BMC Psychiatry, 12, 185. http://dx.doi.org/10.1186/1471-244X-12-185

[25] Mason, O. and Hargreaves, I. (2001) A Qualitative Study of Mindfulness-Based Cognitive Therapy for Depression. British Journal of Medical Psychology, 74, 197-212. http://dx.doi.org/10.1348/000711201160911

[26] Karlsson, G. (1993) Psychological Qualitative Research from a Phenomenological Perspective. Alqvist \& Wiksell International, Stockholm.

[27] Edebol, H., Bood, S.Å. and Norlander, T. (2008) Chronic Whiplash Associated Disorders and Their Treatment Using Flotation-REST (Restricted Environmental Stimulation Technique). Qualitative Health Research, 18, 480-488. http://dx.doi.org/10.1177/1049732308315109

[28] Niklasson, M., Niklasson, I. and Norlander, T. (2010) Sensorimotor Therapy: Physical and Psychological Regressions Contributes to an Improved Kinesthetic and Vestibular Capacity in Children and Adolescents with Motor Difficulties and Concentration Problems. Social Behavior and Personality, 38, 327-346. 
http://dx.doi.org/10.2224/sbp.2010.38.3.327

[29] Nordén, T., Eriksson, A., Kjellgren, A. and Norlander, T. (2012) Involving Clients and Their Relatives and Friends in the Psychiatric Care: Case Managers' Experiences of Training in Resource Group Assertive Community Treatment. PsyCh Journal, 1, 15-27. http://dx.doi.org/10.1002/pchj.1

[30] Nyklicek, I. (2010) Mindfulness, Emotion Regulation and Well-Being. In: Nyklícek, I., Vingerhoets, A. and Zeelenberg, M., Eds., Emotion Regulation and Well-Being, Springer Science and Business Media, New York, 101-118.

[31] Bränström, R., Kvillemo, P., Brandberg, Y. and Moskowitz, J.T. (2010) Self-Report Mindfulnes as a Mediator of Psychological Well-Being in a Stress Reduction Intervention for Cancer Patients. A Randomized Study. Annals of Behavioral Medicine, 39, 151-161. http://dx.doi.org/10.1007/s12160-010-9168-6

[32] Rosenkranz, M.A., Davidson, R.J., MacCoon, D.G., Sheridan, J.F., Kalin, N.H. and Lutz, A. (2013) A Comparison of Mindfulness-Based Stress Reduction and an Active Control in Modulation of Neurogenic Inflammation. Brain, Behavior, and Immunity, 27, 174-184. http://dx.doi.org/10.1016/j.bbi.2012.10.013

[33] Marmarosh, C., Holtz, A. and Schottenbauer, M. (2005) Group Cohesiveness, Group-Derived Collective Self-Esteem, Group-Derived Hope, and the Well-Being of Group Therapy Members. Group Dynamics: Theory, Research, and Practice, 9, 32-44. http://dx.doi.org/10.1037/1089-2699.9.1.32

[34] Chambers, R., Gullone, E. and Allen, N.B. (2009) Mindful Emotion Regulation: An Integrative Review. Clinical Psychology Review, 29, 560-572. http://dx.doi.org/10.1016/j.cpr.2009.06.005

[35] Baer, R.A. (2003) Mindfulness Training as a Clinical Intervention: A Conceptual and Empirical Review. Clinical Psychology: Science and Practice, 10, 125-143. http://dx.doi.org/10.1093/clipsy.bpg015

[36] Nydahl, O. (2008) The Way Things Are. O Books, London.

[37] Blackledge, J.T. and Hayes, S.C. (2001) Emotion Regulation in Acceptance and Commitment Therapy. Journal of Clinical Psychology, 57, 243-255. http://dx.doi.org/10.1002/1097-4679(200102)57:2<243::AID-JCLP9>3.0.CO;2-X

[38] Teasdale, J.D. (1999) Metacognition, Mindfulness and the Modification of Mood Disorders. Clinical Psychology and Psychotherapy, 6, 146-155. http://dx.doi.org/10.1002/(SICI)1099-0879(199905)6:2<146::AID-CPP195>3.0.CO;2-E

[39] Shapiro, S.L., Carlson, L.E., Astin, J.A. and Freedman, B. (2006) Mechanisms of Mindfulness. Journal of Clinical Psychology, 62, 373-386. http://dx.doi.org/10.1002/jclp.20237

[40] Wells, A. (2009) Metacognitive Therapy for Anxiety and Depression. The Guilford Press, New York.

[41] Hayes, S.C., Luoma, J., Bond, F., Masuda, A. and Lillis, J. (2006) Acceptance and Commitment Therapy: Model, Processes, and Outcomes. Behavior Research and Therapy, 44, 1-25. http://dx.doi.org/10.1016/j.brat.2005.06.006

[42] Feldman, C. and Kuyken, W. (2011) Compassion in the Landscape of Suffering. Contemporary Buddhism: An Interdisciplinary Journal, 12, 143-155. http://dx.doi.org/10.1080/14639947.2011.564831

[43] Leary, M.R., Tate, E.B., Allen, A.B. and Hancock, J. (2007) Self-Compassion and Reactions to Unpleasant Self- Relevant Events: The Implications of Treating Oneself Kindly. Journal of Personality and Social Psychology, 92, 887-904. http://dx.doi.org/10.1037/0022-3514.92.5.887

[44] Gilbert, P. (2009) The Compassionate Mind. Constable, London.

[45] Trungpa, C. (1973) Cutting through Spiritual Materialism. Shambhala Publications, Boston.

[46] Lutz, A., Brefczynski-Lewis, J., Johnstone, T. and Davidson, R.J. (2008) Regulation of the Neural Circuitry of Emotion by Compassion Mediation: Effects of Meditative Expertise. PLoS ONE, 3, el897.

[47] Slagter, H.A., Lutz, A., Greischer, L.L., Francis, A.D., Nieuwenhuis, S., Davis, J.M. and Davidson, R.J. (2007) Mental Training Affects Distribution of Limited Brain Resources. PLoS Biology, 5, e138. http://dx.doi.org/10.1371/journal.pbio.0050138 
Scientific Research Publishing (SCIRP) is one of the largest Open Access journal publishers. It is currently publishing more than 200 open access, online, peer-reviewed journals covering a wide range of academic disciplines. SCIRP serves the worldwide academic communities and contributes to the progress and application of science with its publication.

Other selected journals from SCIRP are listed as below. Submit your manuscript to us via either submit@scirp.org or Online Submission Portal.
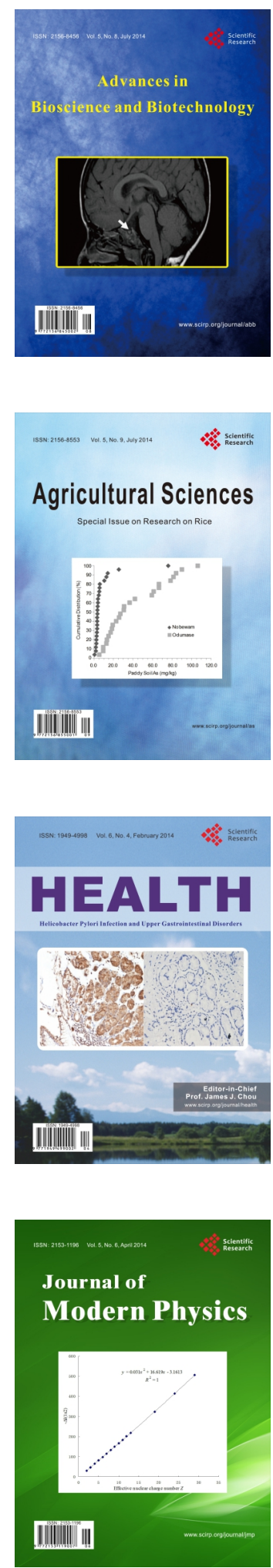
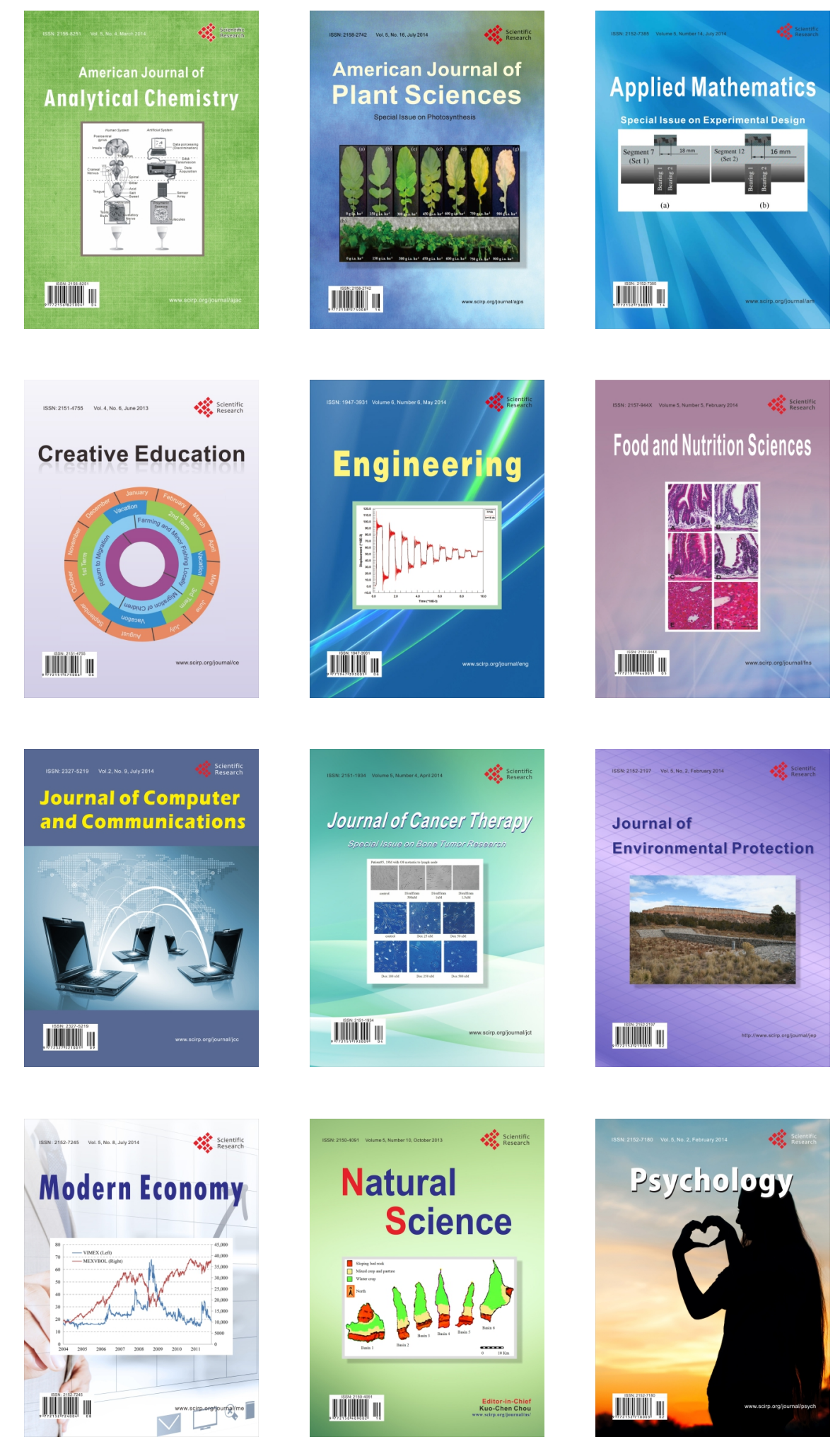